\title{
Childhood Systemic Lupus Erythematosus: A Tertiary Care Centre Experience
}

\author{
Bajracharya $\mathrm{L}^{1}$, Thapa $\mathrm{SB}^{2}$
}

\begin{abstract}
Introduction: Systemic lupus erythematosus (SLE) is a chronic immunologic disorder with multisystem manifestations. Even more awareness is required to diagnose the disease at younger age. Objective of this study was to explore clinico-laboratory manifestations and management of SLE in children at Tribhuvan University Teaching Hospital (TUTH). Materials and Methods: The study was retrospective hospital based study conducted from $15^{\text {th }}$ July, 2008 to $14^{\text {th }}$ July, 2014. Medical charts of all children and adolescent (6-16years of age) with SLE admitted at TUTH were reviewed for analysis of data. Results: The total number of patients was 33 , with $28(84.8 \%)$ girls and $5(15.2 \%)$ boys. The mean age of diagnosis was 12.12 (SD 1.89). Facial puffiness $(27.3 \%)$ and arthralgia (24.2\%) were the commonest presentations at disease onset. The most frequent clinical features during the entire course of illness were edema (78.9\%), anemia (69.7\%) and fever (66.7\%). Twenty three (69.6\%) patients underwent renal biopsy in which class IV was the commonest lupus nephritis. The commonly used drugs after prednisolone were intravenous cyclophosphamide, intravenouse methylprednisolone and mycophenolate mofetil. Total 17 (51.5\%) patients went into remission. Two patients died due to active lupus and four due to sepsis. Conclusion: Lupus nephritis was the commonest feature at disease onset, at the time of diagnosis and throughout the disease course among Nepalese children with SLE. The most frequently used medications were prednisolone and iv cyclophosphamide. Infection and active lupus were the leading causes of complications and death.
\end{abstract}

Key words: ANA, Childhood systemic lupus erythematosus, Lupus nephritis

\section{Introduction}

Cystemic lupus erythematosus (SLE) is a chronic autoimmune $\checkmark$ disease characterized by multisystem inflammation ${ }^{1}$. Flares of the illness can involve any organ system. Diagnosis of SLE often is not made until years after onset of symptoms and so alternate initial diagnoses are frequent. Making a timely diagnosis of SLE and ensuring appropriate early treatment may prevent devastating long-term outcomes. The clinical presentation between adult and
'Dr. Luna Bajracharya, MBBS, MD, Teaching Assistant, ${ }^{2}$ Dr. Surya Bahadur Thapa, MBBS, MD, Lecturer. Both from the Department of Paediatrics, Tribhuvan University Teaching Hospital, Kathmandu, Nepal.

\author{
Address for correspondence: \\ Dr. Luna Bajracharya \\ Tribhuvan University Teaching Hospital, \\ Maharajung,Kathmandu, Nepal \\ Tel No: +9779841313950 \\ Email:Iuna.bajracharya@yahoo.com
}

\section{How to cite}

Bajracharya L, Thapa SB. Childhood Systemic Lupus Erythematosus: A Tertiary Care Centre Experience. J Nepal Paediatr Soc 2015;35(2):111-116.

doi: http://dx.doi.org/10.3126/jnps.v35i2.13282

This work is licensed under a Creative Commons Attribution 3.0 License.

cC) (i)

childhood SLE is similar in many ways. However, features such as mucocutaneous, renal, hematological and neuropsychiatric involvement may be more common in childhood SLE ${ }^{2}$. This article reviews common clinical features and complications of SLE in Nepalese children. The study also briefly addresses available treatment options and outcomes. 


\section{Materials and Methods}

This study was done in Tribhuvan University Teaching Hospital (TUTH) which is a tertiary care hospital in Nepal. The study was carried out after getting proposal approved by Institutional Review Board of TUTH. Medical records of childhood SLE cases from $15^{\text {th }}$ July, 2008 to $14^{\text {th }}$ July, 2014 were obtained. All patients with childhood SLE fulfilled American College of Rheumatology 1982 revised criteria for the classification of systemic lupus erythematosus ${ }^{3}$. Detail clinical informations regarding mucocutaneous, cardiac, pulmonary, musculoskeletal, haematological, renal and neuropsychiatric manifestations etc were recorded in a proforma along with other relevant demographic profile. Laboratory data such complete blood count $(C B C)$, urine routine, culture and 24 hour urine protein excretion, antibodies such as antinuclear antibody(ANA), double stranded deoxyribosenucleic acid (ds DNA), renal function tests, chest X-rays, ultrasound abdomen etc done in each patient were recorded. Renal biopsy reports of those who underwent such procedure were also obtained. Treatments given after the diagnosis of the disease were recorded. Disease remission/ progression on the basis of physical examinations and $\mathrm{CBC}$, proteinuria, creatinine, ds DNA titre etc were also recorded as they came for follow up and medications. The investigations were performed monthly if patient has active lupus, otherwise done 3 to 6 monthly depending on disease activity. The duration of follow up was considered from the time of diagnosis until the patient's last hospital visit. The outcome was classified as $^{4}$ :

a) Remission (normal urinalysis, blood pressure, serum creatinine, no extra renal symptoms)

b) Active disease (proteinuria $>0.5 \mathrm{~g} /$ day, microscopic hematuria $>5$ red cells per high power field, hypertension, extra renal manifestations)

c) Death

d) Lost to follow-up.

SPSS program 17.0 was used for statistical analysis.

\section{Results}

The total number of childhood SLE was 33. Among them, female to male ratio was 5.6:1 ( 28 girls, 5 boys). The mean age of appearance of first symptom was 11.9 years (SD 1.97). The mean age of diagnosis was 12.12 years (SD 1.89). There was an average difference of 3-4 months from the appearance of first symptom to the diagnosis of SLE. The presenting clinical symptoms of children with SLE at disease onset are listed in Table 1.
Table1: First clinical symptom at disease onset

\begin{tabular}{|l|c|}
\hline Presenting first symptom & Number (\%) \\
\hline Facial Puffiness & $9(27.3 \%)$ \\
\hline Joint Pain & $8(24.2 \%)$ \\
\hline Fever & $7(21.2 \%)$ \\
\hline Malar rash & $7(21.2 \%)$ \\
\hline Petechiae rash & $1(3 \%)$ \\
\hline Per vaginal bleeding & $1(3 \%)$ \\
\hline
\end{tabular}

Due to various presenting features of SLE only in one fifth of the cases, SLE was made correctly as the first diagnosis. As other clinical features evolved and investigations reports were available, diagnosis was established thereafter. Table 2 shows various diagnosis made in children with SLE when they first arrived at TUTH.

Table 2: Initial diagnosis made in children with SLE

\begin{tabular}{|l|c|}
\hline Initial Provisional Diagnosis & Number (\%) \\
\hline Renal disease & $9(27.3 \%)$ \\
\hline Rheumatic heart disease & $4(12.1 \%)$ \\
\hline SLE & $6(18.2 \%)$ \\
\hline Juvenile idiopathic arthritis & $3(9.1 \%)$ \\
\hline Tuberculosis & $3(9.1 \%)$ \\
\hline Typhoid & $2(6.1 \%)$ \\
\hline Idiopathic thrombocytopenia purpura & $2(6.1 \%)$ \\
\hline Leukemia & $1(3.0 \%)$ \\
\hline $\begin{array}{l}\text { Disease under evaluation when } \\
\text { referred }\end{array}$ & $3(9.1 \%)$ \\
\hline
\end{tabular}

Two patients (6.1\%) were from Kathmandu Valley and the remaining patients were from outside the valley. Need of criteria, mainly laboratory findings to be fulfilled to diagnose a case of SLE and thus the easy availability of such facility in Kathmandu Valley may have attributed to most referrals and late diagnosis till the patients reached TUTH. Late diagnosis led to severe presentations of disease. The clinical characteristics of children with SLE are listed in Table 3 and hematological with immunological findings at the time of diagnosis are shown in Table 4.

Table 3: Clinical features at the time of diagnosis and during the disease course

\begin{tabular}{|l|c|c|}
\hline Clinical feature & $\begin{array}{c}\text { At the time of } \\
\text { diagnosis } \\
\text { Number (\%) }\end{array}$ & $\begin{array}{c}\text { During the } \\
\text { disease } \\
\text { course } \\
\text { Number (\%) }\end{array}$ \\
\hline Constitutional and generalized symptoms \\
\hline Fever & $18(54.5 \%)$ & $22(66.7 \%)$ \\
\hline Lymphadenopathy & $7(21.2 \%)$ & $8(24.2 \%)$ \\
\hline
\end{tabular}




\begin{tabular}{|c|c|c|}
\hline Hepatosplenomegaly & $13(39.4 \%)$ & $18(54.5 \%)$ \\
\hline Weight Loss & $8(24.2 \%)$ & $10(30.3 \%)$ \\
\hline \multicolumn{3}{|l|}{ Organ Involvement } \\
\hline Arthritis/Arthralgia & 15 (45.4\%) & 17 (51.1\%) \\
\hline \multicolumn{3}{|l|}{ Skin involvement } \\
\hline Malar rash & $18(54.5 \%)$ & $20(60.6 \%)$ \\
\hline Discoid rash & 0 & $2(6.1 \%)$ \\
\hline Photosensitivity & $6(18.2 \%)$ & $8(24.2 \%)$ \\
\hline Mucosal Ulceration & $5(15.1 \%)$ & $9(27.3 \%)$ \\
\hline Alopecia & $10(30.3 \%)$ & $12(36.4 \%)$ \\
\hline Petechie & $2(6.1 \%)$ & $2(6.1 \%)$ \\
\hline Raynaud phenomenon & 0 & $1(3 \%)$ \\
\hline Cutaneous vasculitis & $1(3 \%)$ & $2(6.1 \%)$ \\
\hline \multicolumn{3}{|l|}{ Neuropsychiatric disease } \\
\hline Psychosis & 0 & $1(3 \%)$ \\
\hline Seizure & $1(3 \%)$ & $5(15.1 \%)$ \\
\hline \multicolumn{3}{|l|}{ Cardiovascular } \\
\hline Pericardial effusion & $5(15.1 \%)$ & $5(15.1 \%)$ \\
\hline \multicolumn{3}{|l|}{ Pulmonary disease } \\
\hline Pleural Effusion & $9(27.3 \%)$ & $11(33.3 \%)$ \\
\hline \multicolumn{3}{|l|}{ Gastrointestinal disease } \\
\hline Ascitis & $7(21.2 \%)$ & $13(39.4 \%)$ \\
\hline \multicolumn{3}{|l|}{ Renal disease } \\
\hline Edema & $19(57.8 \%)$ & 26 (78.9\%) \\
\hline Gross hematuria & $7(21.2 \%)$ & 13 (39.4\%) \\
\hline
\end{tabular}

Table 4: Hematological and Immunological findings at the time of diagnosis

\begin{tabular}{|c|c|}
\hline Laboratory data & n/N (\%) \\
\hline \multicolumn{2}{|l|}{ Hematological } \\
\hline Anemia & $23 / 33(69.7 \%)$ \\
\hline Thrombocytopenia & $5 / 33(15.2 \%)$ \\
\hline Leucopenia & $7 / 33$ (21.2\%) \\
\hline Lymphopenia & $12 / 33(36.4 \%)$ \\
\hline \multicolumn{2}{|l|}{ Immunological } \\
\hline ANA & $33 / 33(100 \%)$ \\
\hline Ds DNA & $30 / 33$ (91\%) \\
\hline Low C3 level & $10 / 13$ \\
\hline Low C4 level & $3 / 3$ \\
\hline P-ANCA & $2 / 3$ \\
\hline C-ANCA & $0 / 3$ \\
\hline
\end{tabular}

$\mathrm{N}=$ number of patients that were tested, $\mathrm{n}=$ number of patients who tested positive

Urine routine microscopy for protein showed that more than half of the patients (57.6\%) had $\geq 3$ + albumin. 24 hour urinary protein measurement showed nephrotic range protienuria in 18 (54.5\%) of

the patients where as nonnephrotic range protienuira was observed in 12 (36.4\%) of the patients. Three patients had no proteinuria. Gross haematuria was seen in 13 patients (39.4\%). Almost half of the patients (45.5\%) had microscopic hematuria. Granular casts was seen in three patients. 10 patients (30.3\%) developed azotemia during disease process. Haemodialysis was performed in 6 patients of which one patient's dialysis modality was later converted to continuous ambulatory peritoneal dialysis (CAPD). Urine pus cells $\geq 5 \mathrm{hpf}$ was seen in 11 patients (33.3\%) out of which five developed urosepsis showing Escherichia coli as culture positive.

Out of $23(69.6 \%)$ patients, eight patients underwent renal biopsy at the first admission in TUTH. Remaining patients underwent biopsy in subsequent admissions. The various stages of lupus nephritis (LN) based on the World Health Organization (WHO) classification criteria for $L N$ are as shown in the Table 5. More than half of the patients were in class IV. Nephrotic range proteinuria and hypertension was observed in all patients of class IV and V of LN.

Table 5: WHO Histopathologic findings on renal biopsy

\begin{tabular}{|c|c|}
\hline Lupus Nephritis Class & Number (total =23) \\
\hline I & $1(4.4 \%)$ \\
\hline II & $4(17.4 \%)$ \\
\hline III & $3(13.1 \%)$ \\
\hline IV & $13(56.5 \%)$ \\
\hline V & $2(8.6 \%)$ \\
\hline Total & $\mathbf{2 3}$ \\
\hline
\end{tabular}

\section{Treatment modalities}

Various drugs used in the management and different treatment regimens with outcomes are discussed and summarized below in Table 6 and Table 7.

Table 6: Various drugs used in treatment

\begin{tabular}{|l|c|}
\hline \multicolumn{1}{|c|}{ Drug } & Total number $=\mathbf{3 3}$ \\
\hline Oral Prednisolone & $33(100 \%)$ \\
\hline Hydroxychloroquine & $24(72.7 \%)$ \\
\hline Cyclophosphamide (iv) & $24(72.7 \%)$ \\
\hline Methyl prednisolone (iv) & $13(39.4 \%)$ \\
\hline Mycophenolate mofetil (MMF) & $9(27.3 \%)$ \\
\hline Azathioprine & $2(6.1 \%)$ \\
\hline Tacrolimus & $1(3 \%)$ \\
\hline Methotrexate & $1(3 \%)$ \\
\hline
\end{tabular}


Table 7: Treatment regimens and outcomes

\begin{tabular}{|l|c|}
\hline Drugs & Number of patients \\
\hline $\mathrm{P}$ alone & 2 \\
\hline $\mathrm{P}+\mathrm{HCQ}$ & 5 \\
\hline $\mathrm{P}+\mathrm{CYP}$ & 4 \\
\hline $\mathrm{P}+\mathrm{CYP}+\mathrm{HCQ}$ & 4 \\
\hline $\mathrm{P}+\mathrm{CYP}+\mathrm{HCQ}+\mathrm{Aza}$ & 2 \\
\hline $\mathrm{P}+\mathrm{CYP}+\mathrm{MMF}$ & 1 \\
\hline $\mathrm{P}+\mathrm{CYP}+\mathrm{HCQ}+\mathrm{MMF}$ & 2 \\
\hline $\mathrm{P}+\mathrm{MP}$ & 2 \\
\hline $\mathrm{P}+\mathrm{MP}+\mathrm{CYP}+\mathrm{HCQ}$ & 5 \\
\hline $\mathrm{P}+\mathrm{MP}+\mathrm{CYP}+\mathrm{HCQ}+\mathrm{MMF}$ & 3 \\
\hline $\mathrm{P}+\mathrm{MP}+\mathrm{CYP}+\mathrm{HCQ}+\mathrm{MMF}+\mathrm{T}$ & 1 \\
\hline $\mathrm{P}+\mathrm{MTX}+\mathrm{MP}+\mathrm{CYP}+\mathrm{HCQ}+\mathrm{MMF}$ & 2 \\
\hline
\end{tabular}

$P=$ Oral prednisolone, $H C Q=H y d r o x y$ chloroquine, Aza=Azathrioprine, CYP=Cyclophosphamide (iv), $M M F=$ Mycophenolate mofetil, $M P=$ Methyl prednisolone (iv), T=Tacrolimus, MTX=Methotrexate

All patients received oral prednisolone at some stage of their disease. Four patients received non steroidal inflammmary drugs (NSAIDS) and one patient received methotrexate for joint pain. These patients later needed other immunosuppressive drugs for active disease. IV methyl prednisolone was given to 13 patients during their illness for severe disease activity (azotemia). The number of pulse methyl prednisolone doses ranged up to 6 cycles with most patients receiving 3 cycles. Pulse iv cyclophosphamide used ranged to 12 cycles (six monthly cycle and six 3 monthly cycle). Twenty four patients $(72.7 \%$ ) had iv cyclophosphamide of which 5 patients went on remission with monthly iv cyclophosphamide. MMF was used who did not respond even with 3 cycles of iv cyclophosphamide. Five out of 9 patients (who did not respond to iv cyclophosphamide) on MMF went into remission. One patient received tacrolimus as disease flared up after 3 months of MMF, and still has active lupus nephritis. Azathioprine was given in two patients as maintainence therapy even when they respond to monthly 6 cycles of iv cyclophosphamide as their preference to oral medication and they went into remission. Antimalarial drug was used in 24 patients.

Ninteen patients (57.6\%) developed hypertension and received various medications to lower their BP. The most common antihypertensive drug used was enalapril followed by nifedepine and then furosemide.

\section{Clinical Outcomes: Follow Up}

The follow up period ranged from few days to a maximum of five years. Three patients requested referral to other center. Three patients who are greater than 15 years old now are visiting Adult Nephrology OPD in TUTH. Among them, one is on continuous ambulatory peritoneal dialysis and two are on remission. Two patients were lost to follow up. Remaining patients are still on regular follow up to Pediatric OPD. Total 17 patients $(51.5 \%)$ were on remission. Longest hospital stay was 37 days and minimum 36 hours.

Total six patients (18.1\%) died during the six year study period. Six patients needed PICU care of which four patients requiring mechanical ventilation expired. Parents of two critically ill patients requested for no resuscitate status (DNR) and were not admitted in PICU, eventually later expired. Two patients died due to active lupus (acute renal failure leading to pulmonary edema) and four due to sepsis.

\section{Discussion}

Childhood onset SLE is a rare disease but is reported to be comparatively severe than adults in Asians, Africans and Americans ${ }^{5,6}$. Thirty three cases were encountered over the last 6 years (2008- 2014) period in TUTH. Thirty one (93.9\%) of these cases was referral from outside the Kathmandu valley. The mean age at the time of onset of symptoms was 11.9 years while at diagnosis was 12.1 years. This mean age of diagnosis is similar to other studies conducted in various centres ${ }^{7,8}$. The relative high mean age of presentation could be largely because of under reporting or delayed referral to our center. The female to male ratio was 5.6:1 which is consistent with the study done in Oman ${ }^{9}$. This is in contrast with study conducted by Gulay et al in Philipines and Budhathoki et al in Dharan, Nepal showing female: male ratio of $10: 1^{10,11}$. Only in $18 \%$ patients, correct diagnosis was made at the initial presentation in this study. The diagnosis was based on clinical and laboratory parameters fulfilling revised criteria of 1997 American College of Rheumatology for the classification of SLE ${ }^{3}$. Since SLE has myriad systemic symptoms, differential diagnosis could be various. Among various constitutional symptoms, we had fever and malar rash in 18 (54.5\%) of children. These figures are in accordance with lupus literature and other studies done in Asian countries ${ }^{1,9,12,13}$. Hematological manifestation was one of the common laboratory abnormality 23(69.7\%) which was in the form of anemia, leucopenia and thrombocytopenia. This is similar to studies conducted in Kuwait, Oman and China ${ }^{8,9,13}$. In this study, renal involvement in the form of edema 19 $(57.8 \%)$ and hematuria $7(21.2 \%)$ was present at the time of diagnosis. The spectrum of renal involvement in different ethnicities of Asian origin are as shown in the 
studies-China $76.6 \%$, Oman $64 \%$ and Kuwait-29\%8,9,13. These variabilities could be because of referral pattern, ethnic diversity etc. Rheumatological presentation was in the form of arthralgia/arthritis in 15 (45.4\%) children which is similar to study conducted by Carian B Gulay et al in Philipino children ${ }^{10}$. Mucocutaneous involvement was seen in 18 (54.5\%) in the form of malar rash. Other presentations were alopecia, photosensitivity, mucosal ulceration, Raynaud's phenomenon, vasculitic rash and rarely discoid rash. This is in accordance with study done by Agarwal et al in Indian children and Bastug et al in Turkish children ${ }^{4,14}$. Serosal involvement was in the form of pericarditis/effusion 5(15.1\%) and pleural effusion 9(27.3\%). In contrary to studies conducted in India and Canada, neuropsychiatric presentations are minimal in our study which evolved from 3\%-15\% during the clinical follow up ${ }^{15,16}$. The symptoms were headache, psychosis and seizures due to cerebral vasculitis as shown by MRI head of patients.

ANA and anti ds DNA was found in $100 \%$ and 91\% respectively which is similar to lupus literature and other studies in Asian subcontinent and Western world $d^{1,10,12,17}$. Because of economic constraints, other immunological investigations like $\mathrm{C} 3, \mathrm{C} 4$ were not routinely sent but were found to be low amongst those sent.

23(69.6\%) patients underwent renal biopsy during their course to hospital admission. In the initial years of these children's admission, renal biopsy was done in every patient irrespective of renal involvement which was later on indicated especially to patients showing features of nephritis and is now a specific indication for renal biopsy ${ }^{18}$. In few patients, renal biopsy was not performed as they opted to go to other center for treatment, some planned for biopsy but were lost to follow up etc. Among those whose renal biopsy was done, majority $13(56.5 \%)$ were in WHO class IV, followed by 4 (17.4\%) in class II. The occurrence of histological pattern of renal disease in Asian countries shows $39-69 \%$ in class IV followed by other classes as ours $^{9,19}$.

While treating these patients we adopted standard protocol (KDIGO) for WHO class III, IV and V with iv cyclophosphamide $500-750 \mathrm{mg} / \mathrm{m}^{2}$ body surface area monthly for six pulses and then three monthly for 18 months and six monthly for 36 months $^{20}$. MMF was kept after initial three cycles of cyclophosphamide who did not show features of remission or to those who showed at least partial remission (50\% reduction in proteinuria and or $50 \%$ reduction in creatinine value) and affordable to bear the cost of MMF. MMF as a promising option in treating lupus nephritis who are refractory to cyclophosphamide is also shown in a study done in Florida ${ }^{21}$. In this study also, five patients who did not respond even with three cycles of iv cyclophosphamide went to remission only after receiving MMF. Corticosteroid (prednisolone) was started at $60 \mathrm{mg} / \mathrm{m}^{2} /$ day to start and tapered to $10 \mathrm{mg}$ daily during remission. Our strategy was to keep steroid by at least $0.3 \mathrm{mg} / \mathrm{kg}$ even when the patient was in complete remission. Intravenous methylprednisolone was used in 3-5 day pulse in cases of rapidly progressive glomerlonephritis and in patients with suspected lupus flare. Hydroxychloroquine was used in $24(72 \%)$ patients irrespective of renal involvement. Azathioprine was used in few patients who were unaffordable to MMF and as a maintenance therapy in those patients who wish to have oral drug rather than iv cyclophosphamide. Methotrexate was given to a patient who had persistent joint pain. Supportive drugs like enalapril and other antihypertensives were used when necessary.

Infection and active lupus were the leading causes of complication and death in childhood SLE and our observations were also similar in this study ${ }^{14,19}$.

\section{Conclusion}

Childhood SLE is often difficult to diagnose. Patients may have varied features suggestive of SLE as well as other disease. One should suspect SLE even if classical criteria are not fulfilled and follow such patients closely. The most common clinical manifestation at disease onset, at the time of diagnosis and during the entire course of illness in this study was lupus nephritis. It was followed by joint pain,fever and malar rash as common features in presentation. Prednisolone and iv cyclophosphamide were the most frequently used medication. Mycophenolate mofetil seems to be effective to those who are refractory to iv cyclophosphamide. Infection and active lupus were the leading causes of complication and death. More studies with large number of patients will further clarify the scenario of childhood SLE improving its management in Nepal.
Acknowledgements: Nil
Funding: Nil
Conflict of Interest: None
Permission from IRB: Yes 


\section{References}

1. Silverman E, Eddy A. Systemic lupus erythematosus. In: Cassidy JT, Petty RE, Laxer RM. Lindsley, editors. Textbook of pediatric rheumatology. Philadelphia, PA: Elsevier Saunders, 2005.p.315-42.

2. Livingston B, Bonner A, Pope J. Differences in clinical manifestations between childhood-onset lupus and adult-onset lupus: a meta-analysis. Lupus. 2011;20(13):1345-55.

3. Tan EM, Cohen AS, Fries JF, Masi AT, McShane DJ, Rothfield NF, et al. The 1982 revised criteria for the classification of systemic lupus erythematosus. Arthritis Rheum. 1982;25:1271-77.

4. Agarwal I, Kumar TS, Ranjini K, Kirubakaran C, Danda D. Clinical Features and Outcome of Systemic Lupus Erythematosus. Indian Pediatr. 2009;46(17): 711-15.

5. Jakes RW, Bae SC, Louthren W, Mok CC, Navarra SV, Kwon N. Systematic review of the epidemiology of systemic lupus erythematosus in the Asia-Pacific region: prevalence, incidence, clinical features, and mortality. Arthritis care Res (Hoboken). 2012;64(2):159-68.

6. Ramirez Gomez LA, Uribe Uribe O, Osio Uribe O, Grisales Romero H, Cardiel HM, Wojdyla D et al. Childhood systemic lupus erythematosus in Latin America. The GLADEL experience in 230 children. Lupus. 2008;17(6):596-604.

7. Salah S, Lotfy HM, Sabry SM, El Hamshary A, Taher $\mathrm{H}$. Systemic lupus erythematosus in Egyptian children. Rheumatol Int. 2009;29(12):1463-68.

8. Alsaeid K, Kamal H, Haider MZ, Al-Enezi HM, Malaviya AN. Systemic lupus erythematosus in Kuwaiti children: organ system involvement and serological findings. Lupus. 2004;13(8):613-17.

9. Abdwani R, Rizvi SG, El-Nour I. Childhood systemic lupus erythematosus in Sultanate of Oman: demographics and clinical analysis. Lupus. 2008;17:83-86.

10. Gulay C B, Dans L F. Clinical presentations and outcomes of Filipino juvenile systemic lupus erythematosus. Pediatric Rheumatology. 2011;9:7.

11. Budhathoki S, Shrestha P, Bhatta N, Singh R, Kalakheti B, Kumar D et al. Systemic Lupus erythematosus in childhood - a review of 11 patients at a single center in eastern Nepal. Nepal Medical College Journal. 2007;9(3):186-90.
12. Weiss JE. Pediatric Systemic Lupus Erythematosus: More Than a Positive Antinuclear. Pediatrics in Review. 2012;33:62 Available from: http:// neoreviews.aappublications.org/content/33/2/62.

13. Wu XY, Song HM, Zeng $X F, H e ~ Y Y$, Wang $W$, Li F et al. Clinical manifestation, laboratory test, treatment and outcome of neuropsychiatric involvement in pediatric systemic lupus erythematosus patients. Zhonghua Er Ke Za Zhi. 2009;47:286-90.

14. Bastug F, Poyrazoglu H, Gunduz Z, Tulpar S, Duşunsel R. Juvenile Lupus Erythematosus: Fourteen Years of Experience. Turk J Rheumatol. 2011;26(4):308-15.

15. Singh S, Gupta MK, Ahluwalia J, Singh P, Malhi P. Neuropsychiatric manifestations and antiphospholipid antibodies in pediatric onset lupus: 14 years of experience from a tertiary center of North India. Rheumatol Int. 2009;29(12):145561.

16. Benseler SM, Silverman ED. Neuropsychiatric involvement in pediatric systemic lupus erythematosus. Lupus. 2007;16(8):564-71.

17. Descloux E, Durieu I, Cochat P, Vital-Durand $\mathrm{D}$, Ninet J, Fabien $\mathrm{N}$ et al. Influence of age at disease onset in the outcome of paediatric systemic lupus erythematosus. Rheumatology (Oxford). 2009;48(7):779-84.

18. Hahn BH, McMahon MA, Wilkinson A, Wallace WD, Daikh DI,FitzGerald JD et al. American College of Rheumatology Guidelines for Screening, Case Definition, Treatment and Management of Lupus Nephritis. Arthritis Care Res (Hoboken). 2012;4(6):797-808.

19. Lee PY, Yeh KW, YaoTC, Lee WI, LinYJ, Huang $\mathrm{JL}$ et al. The outcome of patients with renal involvement in pediatric-onsetsystemic lupus erythematosus - a 20-year experience in Asia. Lupus.2013;22:1534-40

20. Kidney Disease: Improving Global Outcomes (KDIGO) Glomerulonephritis Work Group. KDIGO Clinical Practice Guideline for Glomerulonephritis. Kidney inter Suppl. 2012; 2: 139-274. Available from http://www.kidney-international.org

21. Pereira $T$, Abitbol CL, Seeherunvong $W$, Katsoufis C, Chandar J, Freundlich $\mathrm{M}$ et al. Three Decades of Progress in Treating Childhood-Onset Lupus Nephritis. Clin J Am Soc Nephrol. 2011;6(9):219299. 